\title{
Solid-Phase Peptide Synthesis and Structural Analyses by Circular Dichroism Spectroscopy of the Cytotoxic D-(KLAKLAK) $)_{2}$ Sequence
}

\author{
Niki Rana and David Sabatino \\ Department of Chemistry and Biochemistry, Seton Hall University, South Orange, NJ, 07079, USA
}

\section{Introduction}

The apoptosis inducing (pro-apoptotic) peptide sequence, D-(KLAKLAK) $)_{2}$, has been classified as a potent antimicrobial agent [1]. Moreover, it was found to trigger cell death in bacteria without inducing cytotoxicity in mammalian cell types. The chemical basis for this selectivity has been associated with the poly(cationic) amphiphilic nature of this peptide sequence, which facilitates cell permeability in negatively charged bacterial membranes and not within the zwitterionic lipid bilayers of mammalian cell types [1,2]. Upon cell internalization, the positively charged D-(KLAKLAK) 2 sequence accumulates on the surface of the mitochondria and induces depolarization of the negatively charged mitochondrial membrane [3]. This depolarization compromises the mitochondrial membrane integrity and triggers the release of cell death effectors, including cytochrome c, second mitochondrial derived activator of caspase and the apoptosis-inducing factor (AIF) which ultimately results in the programmed cell death response [4]. Considering the potential of this antimicrobial peptide sequence in the treatment of infectious diseases, an optimized solid-phase peptide synthesis and structure analyses by Circular Dichroism (CD) spectroscopy is revealed in this study.

\section{Results and Discussion}

The D-(KLAKLAK) $)_{2}$ peptide sequence may prove to be a synthetic challenge by conventional Merrifield peptide synthesis. These types of amphiphilic peptides have been shown to aggregate during the course of peptide synthesis on the non-polar polystyrene-based resins causing diminished purities and yields [5]. Therefore, the polar poly (ethylene) glycol (PEG) resin which was shown to afford excellent crude purities and yields of synthetically challenging amphiphilic peptide sequences was adopted for our solid-phase synthesis strategy [6] (Scheme 1).
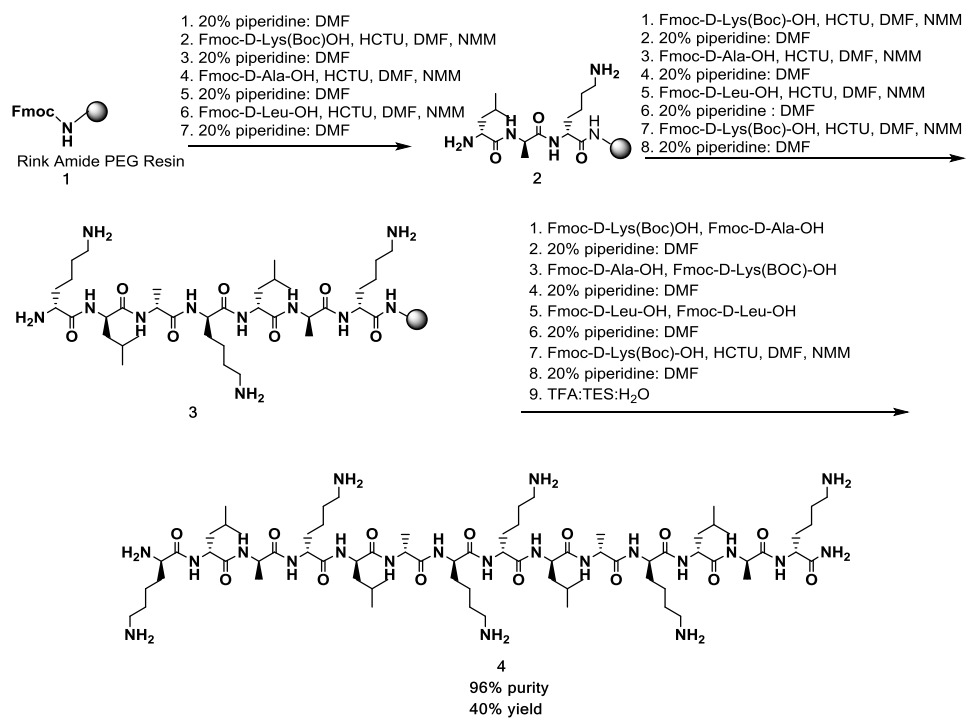

Scheme 1. Solid-phase peptide synthesis of the D-(KLAKLAK $)_{2}$ sequence. 
Peptide synthesis was conducted on a PSI 200C Peptide Synthesizer (Fairfield, NJ) with $O$-(6Chlorobenzotriazol-1-yl)- $N, N, N^{\prime}, N^{\prime}$-tetramethyluronium hexafluorophosphate, HCTU, as activator and coupling reagent, $N$-methylmorpholine, NMM, as base in $N, N$-dimethylformamide, DMF, as solvent for the coupling reactions [5]. The deprotection steps of the fluorenylmethoxycarbonyl, Fmoc, group were completed with piperidine in DMF. Following peptide synthesis, cleavage and deprotection of the peptide from the solid support was achieved with trifluoroacetic acid, TFA, with water and triethylsilane scavenging any unreacted side chain protecting groups (Scheme 1). The desired peptide sequence, $\mathbf{4}$, was synthesized in good purities $(96 \%)$ and acceptable yields $(40 \%)$ following RP-HPLC. Peptide identity was confirmed by molecular weight following LCMS analyses.

The structure and stability properties for the D-(KLAKLAK $)_{2}$ peptide sequence were next evaluated. Circular Dichroism (CD) spectroscopy of the peptide $(30-200 \mu \mathrm{M})$ in water and phosphate buffered saline (PBS) validated the anticipated $\alpha$-helix peptide secondary structure in more dilute conditions $(30 \mu \mathrm{M})$ and $\beta$-sheets at higher concentrations (120-200 $\mu \mathrm{M})$ Figure 1a [1]. Peptide structural stability was next examined with the addition of a surfactant, sodium dodecyl sulfate, SDS, which serves to mimic the cell membrane microenvironment [1]. These conditions demonstrated a stable peptide secondary structure, maintaining the canonical $\alpha$-helix conformation, Figure $1 \mathrm{~b}$. These results demonstrates the adaptive structural properties of this important peptide sequence that are likely needed for cell translocation activity.
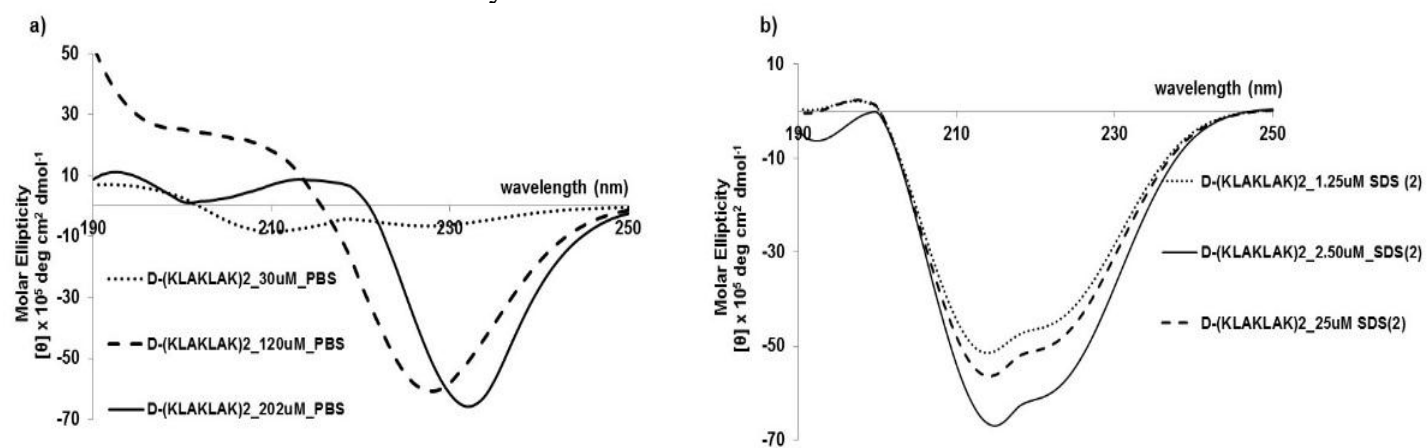

Fig. 1. CD spectroscopy of D-(KLAKLAK)2 in a) PBS (30-200 $\mu M)$ and b) SDS (1.25-25 $\mu M)$.

\section{Acknowledgments}

The authors would like to thank Seton Hall University for continued support. The authors are also grateful to the $24^{\text {th }}$ APS for accommodating our research presentation.

\section{References}

1. Javadpour, M.M., Juban, M.M., Lo, W.C., Bishop, S.M., Alberty, J.B., Cowell, S.M., Becker, C.L., McLaughlin, M.L. J. Med. Chem. 39, 3107-3113 (1996), http://dx.doi.org/10.1021/jm9509410

2. Glukhov, E., Stark, M., Burrows, L.L., Deber, C.M. J. Biol. Chem. 280, 33960-33967 (2005), http://dx.doi.org/10.1074/ibc.M507042200

3. Trapp, S., Horobin, R.W. Eur. Biophvs. J. 34, 959-966 (2005), http://dx.doi.org/10.1007/s00249-005-0472-1

4. Costantini, P., Jacotot, E., Decaudin, D., Kroemer, G. J. Natl. Cancer Inst. 92, 1042-1053, (2000), http://dx.doi.org/10.1093/inci/92.13.1042

5. Joseph, S.C., Blackman, B.A., Kelly, M.L., Phillips, M., Beaury, M.W., Martinez, I., Parronchi, C.J., Bitsaktsis, C., Blake, A.D., Sabatino, D. J. Pept. Sci. 20, 736-745 (2014), http://dx.doi.org/10.1002/psc. 2665

6. García-Martín, F., Quintanar-Audelo, M., García-Ramos, Y., Cruz, L.J., Gravel, C., Furic, R., Côté, S.,

Tulla-Puche, J., Albericio, F. J. Comb. Chem. 8, 213-220 (2006), http://dx.doi.org/10.1021/cc0600019 